\title{
Revealing Children's Experiences and Emotions through Q Methodology
}

\author{
Ingunn T. Ellingsen, ${ }^{1}$ Arlene Arstad Thorsen, ${ }^{2}$ and Ingunn Størksen ${ }^{2}$ \\ ${ }^{1}$ Department of Social Studies, University of Stavanger, 4036 Stavanger, Norway \\ ${ }^{2}$ Norwegian Centre for Learning Environment and Behavioural Research in Education, \\ University of Stavanger, 4036 Stavanger, Norway
}

Correspondence should be addressed to Ingunn T. Ellingsen; ingunn.t.ellingsen@uis.no

Received 3 January 2014; Accepted 7 April 2014; Published 12 June 2014

Academic Editor: Xinyin Chen

Copyright (C) 2014 Ingunn T. Ellingsen et al. This is an open access article distributed under the Creative Commons Attribution License, which permits unrestricted use, distribution, and reproduction in any medium, provided the original work is properly cited.

Over the last two decades, there has been a greater readiness to view children as competent contributors to our understanding of children's lives and experiences. As a consequence of this, we have witnessed an increased focus on including children in research. When research aims at revealing children's perspectives, experiences, and emotions, we need to employ methods that are easy-touse means for obtaining their stories. In this paper, we argue that Q methodology is particularly suitable for facilitating children's participation in research. We will give a brief presentation of the methodology and demonstrate its relevance for research with children. We do so by presenting two research examples aiming at revealing children's experiences and emotions in challenging life circumstances. In the first example, Q methodology was used with five-year-old children where the research topic was divorce. The second example is a study on family perceptions among adolescents in foster home care.

\section{Introduction}

Much evidence confirms that social and emotional adjustment affects the daily lives of children and adolescents. Children's ability to understand emotions is viewed as an important predictor of development of social competence [1]. The convention of children's rights [2] states that it is important for all children to have the opportunity to express their emotions and views on matters that concern them. However, it is not always easy for children to take part in research and put their feelings into words, especially on sensitive themes such as parental breakup or living in foster care.

In recent years, we have seen an increased interest in including children in research [3-6]. The voice of children may elicit a deeper understanding of their perspectives. It is important for researchers to employ flexible research methods for obtaining children's stories in a nonthreatening way. Obtaining true two-way dialog with children and adolescents requires specific skills on talking with children as well as research methods that facilitate children's perspective. Often when adults ask children open-ended and broad questions (e.g., How was your day?), they can receive very general answers (e.g., It was OK). Asking more concrete questions (e.g., Did you go on the new bikes in daycare today? How was it?) can often generate more elaboration and more specific answers. Still, both in research and in life in general, it is important that adults do not lead children into answers that are not necessarily representative of their actual experiences.

Another way of opening up for children to share their experiences is to expose them to stimuli that may encourage their reflections and that may help them to sort and express what they think and feel in a systematic manner. Q methodology may be one approach to do so. Q methodology is designed to reveal subjectivity, such as viewpoints, attitudes, beliefs, opinions, and other subjective aspects of social life [7-9]. Participants in Q methodological studies are exposed to a set of cards containing subjective statements or visual images which they can relate to subjectively. The approach is considered to be a sensitive way of gathering data from children on themes that may be difficult to express [10]. 
The aim of this paper is to discuss how Q methodology can be used in participatory research with children. We will also give two examples of how this has been done: (i) from a study with five-year-old children [11] and (ii) from a study with adolescents aged 13-18 years [12]. We argue that Q methodology offers potential benefits in research with children.

\section{The Importance of Participatory Research with Children}

Over the recent years, children's perspectives have been given more weight in everyday life and in research. This may be seen in relation to what has become known as the "new social studies of childhood" $[13,14]$, and several researchers have described this as a shift in how to view children. Some have even described this change as a new paradigm embracing children as competent actors in their own lives $[4,15,16]$. Whether or not we see this trend as a paradigm, the focus has led to a greater readiness to view children as competent actors in their own lives and has contributed to bringing about an increase in research projects that include children as core participants [17]. These changes are reflected in theoretical perspectives and importantly in legal rights for children. The UN Child Convention Article 12 states that children, depending on age and maturity, should have their say in matters affecting them [2]. In 2003, the child convention was incorporated into Norwegian laws, leading to changes in several areas in order to harmonize Norwegian law with the constitutional rights laid down in the convention. Despite increasing levels of acknowledgement of the importance of including children's perspective in research and in areas affecting children and young people, there still seems to be a tendency to view children and their experiences from an adult point of view [17]. Children can bring about new insights as they may view things more differently than adults. Understanding how children experience their life is important, particularly when the children are exposed to difficult situations. Insights in their understandings and experiences may often give important directions in how to approach and support children experiencing challenging lifesituations.

Children may be studied using different perspectives. When we view children from an adult perspective, the children easily become an "object" for research. Only when significant emphasis is placed on the presence of the child's voice throughout the research process, the children will be included as subjects in research $[17,18]$. Sommer et al. [6] make a distinction between a "child perspective" and a "children's perspective" to illustrate the difference between the cases when children are being "objects for research" as opposed to them being "subjects in research." The terms "child perspective" and "children's perspective" are widely used but not always clearly defined. Sommer et al. [6] provide the following definition of the distinction between these perspectives.

"Child perspective" directs adult's attention towards an understanding of children's perceptions, experiences, and actions in the world. Despite child perspectives' attempt to get as close as possible to children's experiential world they will always represent adult's objectification of children. By contrast children's per spectives represent children's own perceptions, experiences, and understanding of their lifeworld [6, p. 198].

Notably, a child perspective is the adult's attention towards understanding the life of children. A key criterion for a child perspective is according to Sommer et al. [6, p. 22] that it is "created by adults who are seeking deliberately and as realistic as possible, to reconstruct children's perspectives." This differs from an adult perspective on children deriving from adult's reconstruction of what they think is the child's perspective or what they believe is best for the child. In contrast, children's own perspectives can solely be expressed by the children themselves. We do not intend to claim that it is wrong to hold an adult perspective. Adults can also bring about important knowledge, and there will be times when adults must act on the basis of adult knowledge and experience in order to protect children from danger and harm [19]. However, our intention is here to stress that there are important distinctions between different perspectives that we need to be aware of. Including children's perspectives in research can give important knowledge that can easily be missed out if researchers solely rely on adult's reconstruction of children's perspectives. That said, it is only the children themselves that fully can have a "children's perspective" and also researchers seeking to elicit children's perspectives will inevitably interpret their stories through adult lenses. The primary intent in this paper is to illustrate the usefulness of Q methodology in engaging children and in helping them to express their perceptions, emotions, and how they experience their world in certain life circumstances.

Putting feelings and emotions into words, especially on sensitive themes such as family change, may be difficult as one adolescent in our example study on foster home placement expressed it: "It is difficult to explain, because I do not know which words I can use." For some children, participation in research can be an emotional and intrusive experience, causing difficult feelings to arise. Researchers need to show sensitivity in all research but particularly in research with children and a strategy often used is to invite children to talk about their participation. This may be one way to discern whether the children need someone else to talk to after the research assessment session. When including children's voices in research, it is a priority to use a child-friendly research methodology.

\section{Limitations of Traditional Research Methodologies in Achieving Children's Perspectives}

Children are often considered to be a particularly sensitive group of research subjects who place extra demands on researchers' ethical considerations when designing the methodological instruments [20, 21]. Many traditional 


\begin{tabular}{|c|c|c|c|c|c|c|c|c|}
\hline \multicolumn{8}{|c|}{ Most unlike } & \multirow{2}{*}{$\begin{array}{c}\text { Most like } \\
4\end{array}$} \\
\hline-4 & -3 & -2 & -1 & 0 & 1 & 2 & 3 & \\
\hline & & & & & & & & \\
\hline & & & & & & & & \\
\hline & & & & & & & & \\
\hline & & & & & & & & \\
\hline & & & & & & & & \\
\hline
\end{tabular}

Figure 1: An example of a Q sort grid where the instruction could be to sort the cards in accordance with what is most like or most unlike “..." (e.g., "the way I feel," "my experience").

research approaches, within both the qualitative and quantitative paradigms, require specific skills from participants. Qualitative approaches, such as in-depth interviews, require relatively good verbal skills. Reading skills are needed to take part in quantitative studies, such as surveys. Quantitative studies also require a large sample of participants to show effects, which can be challenging in child studies. For example, children's participation usually requires consent from caregivers [22], which make it more difficult to achieve large samples. Furthermore, as Scott [23] argues, children are often excluded from large scale quantitative studies because too few research instruments take account of children's developmental level. Children's vocabulary and cognitive level may make it difficult to take part in more conventional research approaches designed for adult participation.

Researchers need to adapt user-friendly approaches that can be well designed for participatory research with children and adolescents [24]. In recent years, we have witnessed a growth in child-friendly research approaches, as researchers have become more aware that it is unacceptable to allow methodological challenges to exclude children from taking part in research. In the following we will describe how Q methodology can represent such a child-friendly approach. Including children's voices to elicit a wider perspective was a goal in two studies using $\mathrm{Q}$ methodology. In one study [11] the focus was on five-year-old children's experiences and emotions related to parental breakup. In another study [12], adolescents' (age 13-18) experiences related to family perceptions when living in foster care were explored. In both these studies, Q methodology was applied to reveal subjective emotions and views among the children. Before going further and discussing the relevance of $\mathrm{Q}$ when exploring children's experiences and emotions through these studies, we will provide a brief summary of the research process in $\mathrm{Q}$ methodological studies.

\section{Q Methodology}

Q methodology is designed to explore and investigate patterns of subjectivity such as shared views, attitudes, beliefs, opinions, and other subjective aspects of social life $[8,25]$. The methodology was introduced by William Stephenson in the 1930s [7] and is gaining grounds as researchers become more and more aware of the advantages of $\mathrm{Q}$ methodology.

It is common to organize a $\mathrm{Q}$ study into certain steps $[26,27]$. The first step is to identify the flow of communication surrounding the research topic, such as views, attitudes, perspectives, and vantage points on an issue [8]. This is referred to as identifying the concourse [7], and this may typically be done through personal interviews or by collecting statements from literature or media. Subsequently, a representative sample of statements is drawn for the present Q study. The next step is to arrange for Q sorting with participants. In this process the participants are given the opportunity to express their perspectives through sorting of the statements in accordance with how they relate themselves to different aspects of the topic covered by the statements. Finally, all the individual Q sorts are analyzed (through byperson factor analysis) and the interpretation begins.

Statements in a Q study are most often written statements, but may also very well be visual statements such as images or objects. The essence is that the total number of statements must make it possible to elicit different perspectives through the point of the participants' self-reference [28]. The complexity and number of the statements will depend on the cognitive and developmental level of the participants, but the final sample of statements normally consists of between 20 and 50 statements $[25,29]$.

In the $\mathrm{Q}$ sorting process, the participants are asked to sort the cards in accordance with a specific instruction into a predesigned matrix (see Figure 1). A typical instruction could be "Sort the cards according to what is most like and most unlike your everyday feelings" or "Sort the cards in accordance with/of what is most like/unlike your situation." The matrix has typically quasinormal shape, with one area to place statements that are most agreeable, or "most like me" on one side, and another area for most disagreeable statements (or "most unlike me"). The further to the right in the matrix, the more the person sorting "agrees" with the statements, and the further to the left, the more the person "disagrees" with them. The center of the matrix constitutes statements perceived as more neutral or undecidable.

The procedure of sorting the statements or images is often referred to as a $\mathrm{Q}$ sorting procedure. When all the statements are placed into the matrix, this constitutes the $\mathrm{Q}$ sort and reflects the person's subjective view about the topic. Additionally, participants are often given an opportunity to comment and elaborate on their positioning of the statements after completing the Q sort. Oftentimes comments are recorded as a supplementary data source, and some researchers even do active postsorting interview with the participants. In postsorting interviews, the participants may for example be asked to comment on statements that are on the most like/unlike side of the grid. Such comments can 


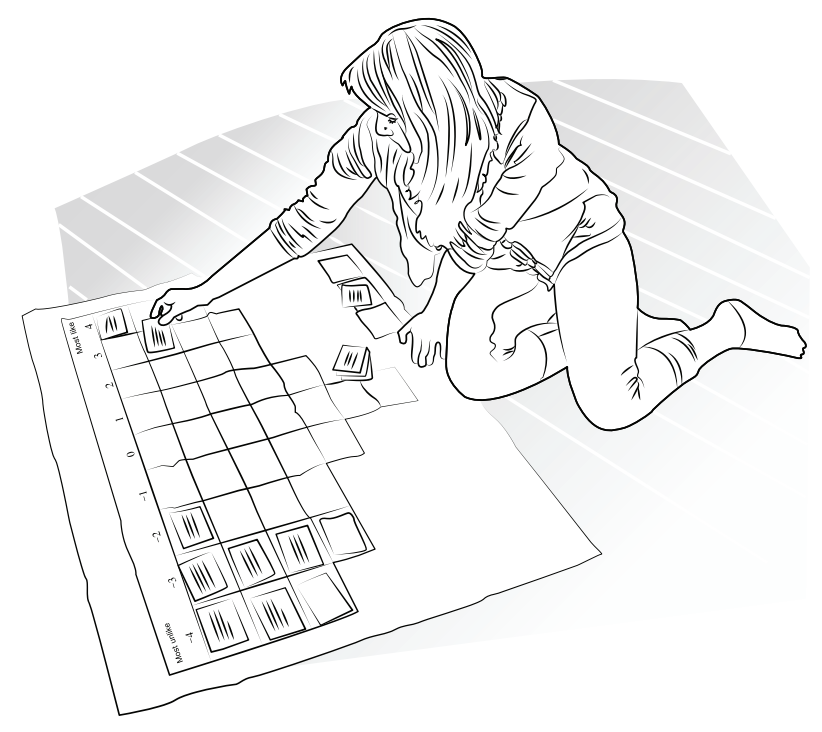

FIgURE 2: An illustration of a Q sorting situation (illustration by Ingunn T. Ellingsen and Ole A. Hauge).

be very helpful in order to discover the rationale behind the positioning of the statements into the matrix [30]. Figure 2 illustrates a Q sorting situation with an adolescent sorting a set of statements into a Q sort matrix.

$\mathrm{Q}$ methodology combines quantitative and qualitative techniques, and some even claim that it goes beyond the quantitative and qualitative distinction [31]. This is because the quantitative and qualitative aspects are merged into one approach. Each Q sort is registered and analyzed through byperson factor analysis, and the results reveal how individuals that express similar experiences or emotions are grouped into the same factor. To be more specific, if two persons $Q$ sorts are similar (but not completely identical), they will correlate highly and will end up on the same factor. These two people share central aspects of their subjectivity and will therefore influence the structure of the same general factor together with others sharing similar views. Factors are often also called views or viewpoints in $\mathrm{Q}$ methodological studies, since their content reveal general views that participants on this factor share.

Furthermore, the results also reveal divergences between participants, which also may give important insights. In this manner central viewpoints among participants are disclosed in a systematic way. When interpreting the emerging factors, we search for the overall configuration of meaning that lies in the factor, as well as what the different factors have in common and what distinguishes one factor from another. Along with comments that participants give to their sort, the researcher will have a rich material for interpretation.

In the following text we will demonstrate how $\mathrm{Q}$ methodology was used with children and adolescents in two different studies. In both studies, the research topic touched upon sensitive issues. The Q sorting procedure gave the participating children an opportunity to express their perspectives without necessarily articulating the feelings or emotions into their own words or without going into extensive details. We will first give a brief presentation of the child study on parental breakup, followed by the adolescent study on foster home placement. We will use these studies as examples of how $\mathrm{Q}$ methodology can be used when researching children's emotions and feelings.

\section{The Child Q Study $(N=37)$}

In Norway-as in the rest of Europe and the United Statesdivorce rates are generally high. In the Norwegian culture it is expected that as much as $45 \%$ of couples who marry will eventually end up getting a divorce [32]. In a research project named BAMBI that focused on young daycare children of divorce we wanted to include the voices of young children and people in their surroundings, and therefore we conducted a range of qualitative studies not only among daycare staff, parents, and family therapist, but also with the children themselves. The multi-informant design was set up to explore various challenges and solutions related to daycare centers' approach to children and families of divorce. All informant groups contributed with unique and important insight into this theme, and including the children themselves as informants resulted in some unexpected points. These were integrated in the future development of materials to help daycare workers in their work with children who experience parental breakup and to parents experiencing divorce (a picture book to children, an instruction manual to daycare staff, and a pamphlet to parents).

Our research approach when collecting data from the young children was to utilize $\mathrm{Q}$ methodology with visual images. This use of visual images is not very common but has been seen in a few other previous studies $[33,34]$. The images in the child Q study were based on statements from theory, and a Fisher balance block design (see [9]) was constructed based on the theoretical dimensions to ensure representativeness. This helped the researchers to draw diverse statements from the concourse. A total of twenty statements were drawn and subsequently converted into images by a professional designer in collaboration with the researchers and produced as picture cards. These were then piloted with five children. Some minor adjustments were necessary before the final data collection.

The child study included 37 five-year-old children. Approximately half of the children $(n=17)$ had experienced parental breakup or divorce, and the rest $(n=20)$ had no such experience. The children were presented with the 20 visual images printed on cards that illustrated various emotions and experiences that might be related to parental divorce. The main content of the cards could be either positive (e.g., joy or play) or negative (e.g., grief or anger) (see Figure 3).

We took time to go through a carefully prepared protocol that was established to make sure the children felt safe and that they were familiar with various feelings (e.g., how do we look when we are happy? how do we look when we are sad?). We also took time to ensure that they understood the instructions. In line with ethical decisions, the researchers did not want to ask the children directly about parental breakup, but they knew which parents were divorced [20]. The cards 


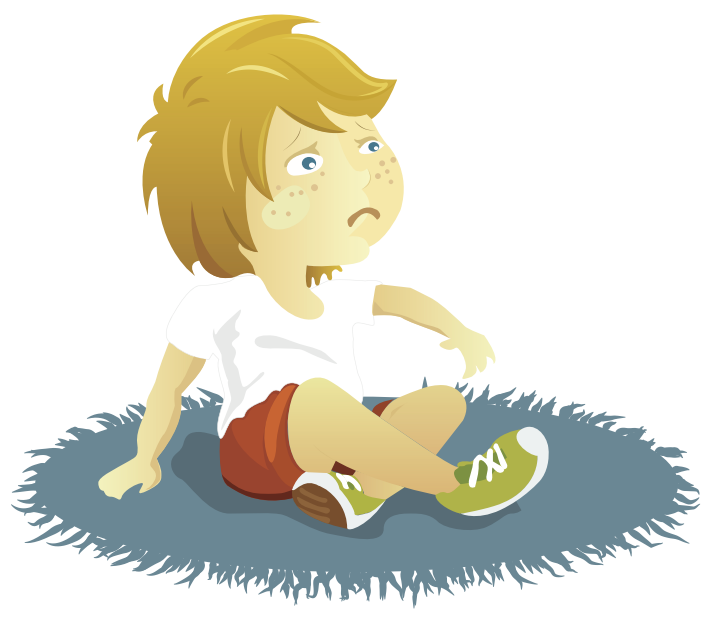

5

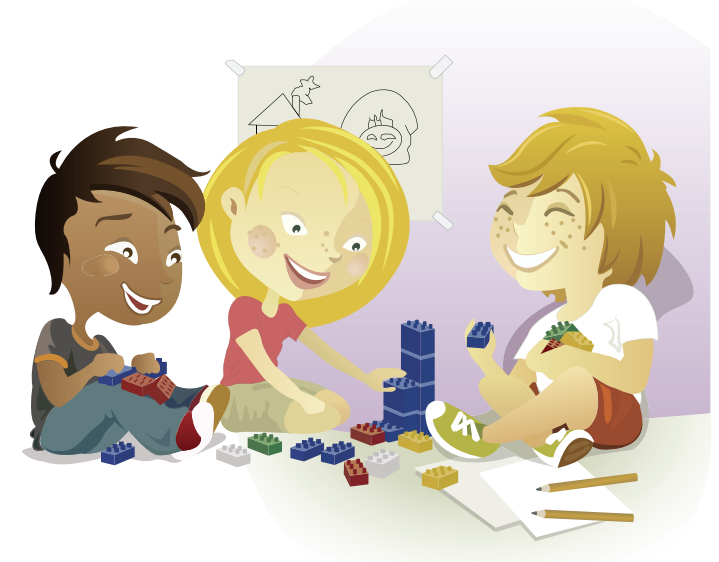

13

FIGURE 3: Two of the statements used in the child study, one indicating feeling sad and alone and the other indicating cheerful play with other children (illustrations belong to the Norwegian Centre for Learning Environment and Behavioural Research in Education and are made by Ole A. Hauge).

illustrated a variety of child emotions and also situations of harmony and conflicts in family life. Subsequently, the children were asked to point out cards that they believed were "most like" and "most unlike" their everyday experiences and feelings, which subsequently were placed into the grid. Our experience was that the children managed to express their feelings and experiences in a reliable way through this research approach [35], although they needed guidance from the researcher to relate to the instructions for sorting cards. It was apparent that some children were emotionally challenged by some pictures, and it was necessary to apply a very sensitive approach to help and support them along the way. For instance one child commented "nobody could comfort me, because they were simply too busy." Still, our general impression was that these five-year-old children enjoyed the procedure of sorting the images as an exciting challenge. Some children were quite talkative during the process, while others were quieter and concentrated deeply on where to put the cards in the grid. Using images instead of questions helped both children that had limited vocabulary and children for whom this theme was emotionally challenging to express their experiences. When the children had finished sorting the cards, they were asked to look at the whole display of pictures to see if they needed to change anything to depict their view. Some expressed that the Q sort represented their experiences, but they did not want to talk about it. Other children were tired after the Q sort but were satisfied with the way they had sorted the cards.

All 37 Q sorts done by the children were analyzed with Q methodological principles, and the results clearly enlightened new themes that would not have been detected by merely studying parents and teachers.

The study revealed three viewpoints among the children.

(i) "Well adjusted": the children on this factor (or view) reported through their $\mathrm{Q}$ sortings to have many close relationships with parents, extended family, and friends. The other striking thing with this view is that the children agreed to have many happy feelings and no difficult or conflicting feelings. Both children of divorce and other children defined this factor, but it consisted mostly of children with no divorce experience.

(ii) "Mixed feelings": this view is characterized by mixed feelings. Children loading significantly on this factor expressed that they often can feel happy, anxious, angry, or sad. Close relationships did not seem very dominant for the children. More children of divorce than other children defined this factor.

(iii) "Sadness": the children with this view felt close to both parents, but at the same time (or maybe as a consequence of this closeness) noticed grief and sadness in their parents. They also reported feeling sad and lonely themselves. Two children of divorce defined this factor.

A general pattern was that children with no divorce experience were more prone to load highly on the first factor ("Well adjusted") and children that had experienced parental breakup or divorce seemed more disposed to load highly on the two other factors ("Mixed feelings" or "Sadness"). For a more fully presentation of this specific study, see [11].

\section{The Adolescent $Q$ Study $(N=22)$}

This study focuses on the perception of family among adolescent in long-term foster home placement. In Norway, about 8,000 children live in foster homes (about 3,300 in the age group 13-17). Most of the foster home placements are compulsory placements made by court order, accounting for about 7.2 per 1,000 children. In Norwegian child welfare policy, considerable attention is paid to the relation between 
biological parents and children, and in most cases children have regularly contacted with their birth parents (unless safety reasons advice against it). In Norway, adoptions of foster children are very rare. This policy may influence how children perceive family while being in foster care.

In this study we explored the views and feelings about "family" among 22 adolescent foster children in age group 1318 who sorted 39 written/verbal statement cards. These were generated from preinterviews with foster children (individual interview), foster parents (focus group interview), and birth parents (focus group interview). The statements contained different themes such as belonging and identity, relationships in everyday life and in the future, and emotional statements, such as, statements about conflict and feeling different. A Fisher balance block design was also used in this study to select statements that could represent this variety of relevant issues. All of the adolescents had lived in the foster home for more than three years and had visiting arrangements with their birth family. As in the child study, the adolescents where asked to sort the statements into a predefined grid indicating where to put statements perceived as "most like my situation" and "most unlike my situation." Three viewpoints were revealed.

(i) "Confidence and well-adjustment": adolescents associated with this factor held an inclusive family perspective, with feelings of being loved by both birth and foster family. The configuration of the statements gives a relatively strong impression that these adolescents felt secure and confident, and they felt loved by both birth and foster parents. Fifteen of the 22 participants correlated significantly with this factor.

(ii) "Strong feelings of membership to birth family": children loading significantly on this factor felt an insecure bonding to foster family, and feelings of family refer almost entirely to the birth family. These children revealed strong feelings of loyalty towards birth family, which may have prevented them from attaching to the foster family. Four adolescents were associated with this perspective.

(iii) "Strong feelings of membership to foster family": children loading significantly on this factor had no sense of family belonging to birth family and found contact with birth family stressful. However, the overall configuration of the factor reveals a strong and secure family bonding to the foster family. Three of the adolescents were associated with this perspective. [12].

For a more fully presentation of this specific study, see

\section{What Are the Advantages of Q Methodology in Researching Children's Experiences and Emotions?}

Based on these studies among children and adolescents, we have experienced that $\mathrm{Q}$ methodology provides an efficient and suitable way of including children in research. Not only is it considered as a child-friendly approach, but it is also a way of obtaining the children's story in a nonthreatening way. One reason for this is that the participants do not have to verbalize their experiences themselves. It seems to be easier relating their feelings to a fixed set of statements than finding the words to describe their experiences. Some of the adolescents expressed that they would have been reluctant to participate in research if they had to elaborate on their situation verbally. Relating to a set of statements was found to be easier and less intrusive than expressing their experiences and emotions into their own words, as confirmed by one of the adolescents "This was a really clever way of doing it. This may actually give you a better feeling of what information you have given up compared to if you just sit and talk freely." For young children, such difficulties can also be due to developmental issues. Theoretically, language can be divided into two categories: receptive and expressive language. Receptive language refers to the ability to comprehend spoken language, while expressive language is the ability to express oneself in words [36]. Children's receptive vocabulary is often more developed than children's expressive vocabulary, as expressive language requires the ability to make phonological representations of what one wants to express [37]. Hence, sorting cards can be a way of expressing experiences without having to use words. That said, a crucial point is that the set of statements contain the variety needed in order to elicit what participants want to express. When heterogeneity is ensured, Q methodology can provide a holistic view and can reveal details that may be missed out using more conventional approaches.

Q methodology can easily be adjusted to the children's age and developmental stage. As illustrated by one of our studies, even very small children can take part in research with relative ease. The flexibility that $\mathrm{Q}$ methodology holds when it comes to the level of complexity in the Q sample makes it particularly suitable for research with children. When developing the statements, one needs to take the participants age and developmental stage into account. Visual images can be useful when including children who have not yet learned to read. However, developing visual statements will demand more effort from the researchers to make sure that the images have a clear content. When this is done, visual images can be powerful expressions of experiences and emotions. Through Q methodology, one can incorporate theory into the statements or images relative to the theme in question, without invading the children's feelings regarding sensitive themes. The aim is to make it easier to express difficult issues. At the same time, the participants have the opportunity to add information verbally if they wish to do so. Such comments are valuable when interpreting the emerging perspectives as they may elicit a deeper understanding of the children's views. Certain statements made some children stop and dwell more than other statements. Such statements seemed to be a door opener to elaborate on specific themes considered important to the child. In this way, the method allows for adjusting the approach to each individual participant, and the sorting procedure may function as a communicative tool in research. Even though the sorting procedure seemed to help the participants to elaborate on important issues in the statements, children who were reluctant to or had difficulties 
expressing their feelings into words could still participate by just sorting the images or statements. The Q sort is just as valid for children that do not give supplementary comments and elaborations.

Q methodology reveals subjective feelings and understandings from a self-referent standpoint. The sorting procedure may actually also help the children to reflect upon their own experiences and emotions. The importance of understanding emotions can be seen in relation to newer contributions within attachment theory. Fogany's concept of mentalization is seen as an important competence in understanding behavior related to feelings and emotions [38]. Mentalization "refers to the capacity to envision mental states in oneself and another, and to understand one's own and another's behavior in terms of underlying mental states and intentions" [39]. The ability to metacognitively reflect upon oneself as well as others may be seen as a crucial resilience factor that enables us to understand ourselves in relation to others. Mentalization is seen as a key competence in the regulation of emotions [40], and the ability to understand emotions is viewed as an important predictor of socioemotional competence and adjustment [1]. This way, taking part in research can also be a valuable experience for children.

In $\mathrm{Q}$ methodology, subjectivity is preserved throughout the analysis, as the entire $\mathrm{Q}$ sort from each participant is subjected to factor analysis. Hence, biases related to the researchers' preconceptions of central themes are reduced, which gives children an opportunity to elicit their views and experiences without the risk that the researcher reconstructs their story into specific categories. The emerging factors are solely based on how the children sort the cards, which means that the structure of the factors is a result of the children's views and their resemblance or divergence with other participants' views. When supplementary comments are given, these do not have impact on the factor structure, but they are helpful in the interpretation of the factors. Still, all research will to some extent be influenced by the researcher conducting the research. Consequently, they need to have an awareness of by what means they influence their research, such as their theoretical perspectives, their presence during data collection, and the way they interpret the results [41].

A challenge in research touching sensitive issues and particularly research with children is to recruit an adequate number of participants for the study. Q methodology can be applied in studies with relatively few participants. Nevertheless, researchers often encounter difficulties gaining access to children. One reason for this is that caregivers and professionals act as gatekeepers when children are invited to take part $[4,42,43]$. When staff leaders were asked if research could be done with children in their daycare, they were quite skeptical. However, when our data collecting procedures were explained and the images and grid were shown to them, they said this was interesting and not invasive (especially since we would not ask questions about divorce). When informing possible gatekeepers about our studies involving children and adolescents, both parents and professionals were reassured because of the procedure of the data collection. It seemed as if they also found the methodological approach well suited for children's participation. Several of the child welfare workers and the daycare teachers expressed that this way of communicating with children on sensitive issues actually could also be helpful in their day-to-day work.

\section{Conclusions}

When studying children's experiences and emotions, researchers need to use methods that are suited for children's participation. Our experience is that Q methodology is well suited to research that involves children because it can offer a nonthreatening and easy-to-use means of obtaining their story. Excluding children from taking part in research because they represent a challenge to traditional research methods does not seem acceptable [24]. Kelly [24] further argues that this imposes a responsibility on researchers to adopt methodological approaches that can allow children and adolescents to participate in research. Taking the child's perspectives into account, researchers need to employ flexible methods that take the child's age and cognitive ability into consideration. Some children find it difficult to talk to strangers about their experiences and emotions, and expressing themselves by relating to a fixed set of statements may make participation less threatening. In our studies, the children expressed the $\mathrm{Q}$ sorting as engaging and a good way of taking part in research.

All methods have their strengths and limitations. When limitations of a method are discussed, there seems to be a tendency that the critics concern aspects that are not the intention of the method, such as the generalizability of qualitative method. Although Q methodology uses statistical procedures for data analysis, it is not possible to generalize findings directly to a greater population. The aim is to explore perspectives and views among the participants. Therefore, the appearing perspectives will depend on how the participants in the specific study think and feel, but it is not unlikely that others may share such views. However, these findings may generate new hypotheses that may be explored in future quantitative research.

As in all research, a careful preparation of the Q study in advance is needed. When conducting $\mathrm{Q}$ methodological studies, the researcher has to be thorough in how to generate the statements for the study. An unbalanced set of statements can cause limitations as it will diminish the participants' opportunity to present their thoughts and views. Interpreting Q data thoroughly is a comprehensive work especially where children are concerned. Stephenson [44] wisely cautions us "to see more, hear more, feel more" before leaping into interpretations. It is also helpful to follow Brown's [41] advice to think through and take into account the researcher's position, especially in an effort to highlight children's perspective.

\section{Conflict of Interests}

The authors declare that there is no conflict of interest regarding the publication of this paper. 


\section{References}

[1] S. A. Denham, Emotional Development in Young Children, The Guildford Press, New York, NY, USA, 1998.

[2] U. Nations, "Convention on the rights of the child," 1998, http://www.ohchr.org/EN/ProfessionalInterest/Pages/CRC .aspx.

[3] P. Baynes, "Untold stories: a discussion of life story work," Adoption \& Fostering, vol. 32, no. 2, pp. 43-49, 2008.

[4] A. James, C. Jenks, and A. Prout, Theorizing Childhood, Polity Press, Cambridge, UK, 1998.

[5] I. Schjelderup, C. Omre, and E. Marthinsen, New Approaches for Child Welfare, Universitetsforlaget, Oslo, Norway, 2005 (Norwegian).

[6] D. Sommer, I. P. Samuelsson, and K. Hundeide, Child Perspectives and Children's Perspectives in Theory and Practice, Springer Link, London, UK, 2010.

[7] S. Brown, Political Subjectivity: Applications of Q Methodology in Political Science, XIV, Yale University Press, New Haven, Conn, USA, 1980.

[8] B. McKeown and D. Thomas, Q Methodology, Sage University Paper: Quantitative Applications in the Social Sciences, University of Iowa, Iowa City, Iowa, USA, 1988.

[9] W. Stephenson, The Study of Behavior: Q-Technique and Its Methodology, University of Chicago Press, Chicago, Ill, USA, 1953.

[10] I. T. Ellingsen, I. Størksen, and P. Stephens, "Q methodology in social work research," International Journal of Social Research Methodology, vol. 13, no. 5, pp. 395-409, 2010.

[11] I. Størksen, A. A. Thorsen, K. Øverland, and S. R. Brown, "Experiences of daycare children of divorce," Early Child Development and Care, vol. 182, no. 7, pp. 807-825, 2012.

[12] I. T. Ellingsen, D. Shemmings, and I. Størksen, "The concept of "family" among Norwegian adolescents in long-term foster care," Child and Adolescent Social Work Journal, vol. 28, no. 4, pp. 301-318, 2011.

[13] S. Greene and M. Hill, "Researching children's experience: methods and methodological issues," in Researching Children's Experiences: Approaches and Methods, S. Greene and D. Hogan, Eds., pp. 1-21, SAGE publications, London, UK, 2005.

[14] G. Halldèn, "Child perspective as an ideological or methodological concept," PedagosIk forsknIng i SverIge, vol. 8, no. 1-2, pp. 12-23, 2003 (Norwegian).

[15] S. Seim and T. Slettebø, User Participation in Child Welfare, Universtitetsforlaget, Oslo, Norway, 2007 (Norwegian).

[16] D. Sommer, Childhood Psycology: Developement within a World in Change, Hans Reitzel, København, Denmark, 2003 (Danish).

[17] P. Christensen and A. James, Research with Children: Perspectives and Practices, Routledge, London, UK, 2008.

[18] P. O. Tiller, Hverandre: en bok om barneforskning, Gyldendal, Oslo, Norway, 1990.

[19] I. T. Ellingsen, P. Stephens, and I. Størksen, "Congruence and incongruence in the perception of "family" among foster parents, birth parents and their adolescent (foster) children," Child and Family Social Work, vol. 17, no. 4, pp. 427-437, 2012.

[20] A. A. Thorsen and I. Størksen, "Ethical, methodological, and practical reflections when using Q methodology in research with young children," Operant Subjectivity, vol. 33, no. 1-2, pp. 3-25, 2010.
[21] I. Literat, "A pencil for your thoughts': participatory drawing as a visual research method with children and youth," International Journal of Qualitative Methods, vol. 12, no. 1, pp. 84-98, 2013.

[22] W. A. Corsaro and L. Molinari, "Entering and observing in children's world: a reflection on a longitudinal ethnography of early education in Italy," in Research with Children: Perspectives and Practices, P. Christensen and J. Allison, Eds., pp. 239-259, Routledge, New York, NY, USA, 2008.

[23] J. Scott, "Children as respondents: the challenge for quantitative methods," in Research with Children: Perspectives and Practices, P. Christensen and J. Allison, Eds., pp. 87-108, Routledge, New York, NY, USA, 2008.

[24] B. Kelly, "Methodological issues for qualitative research with learning disabled children," International Journal of Social Research Methodology, vol. 10, no. 1, pp. 21-35, 2007.

[25] D. Shemmings and I. T. Ellingsen, "Using Q methodology in qualitative interviews," in The SAGE Handbook of Interview Research: The Complexity of the Craf, J. F. Gubrium, Ed., SAGE, 2012.

[26] S. Brown, “A Q methodological Tutorial”, 1991/1992.

[27] J. van Exel and G. de Graaf, "Q methodology: a sneak preview," 2005.

[28] A. A. Thorsen, "A pathway to understanding Q-methodology", Journal of Human Subjectivity, vol. 4, no. 2, pp. 33-53, 2006.

[29] J. C. Donner, "Using Q-sorts in participatory processes: an introduction to the methodology," in Social Analysis: Selected Tools and Techniques, R. A. Krueger, M. A. Casey, J. Donner, S. Kirsch, and J. N. Maack, Eds., Paper Number 36, Social Development Department, The World Bank, Washington, DC, USA, 2001.

[30] K. Gallagher and D. Porock, "The use of interviews in Q methodology: card content analysis," Nursing Research, vol. 59, no. 4, pp. 295-300, 2010.

[31] J. M. M. Good and S. Brown, "The relationship of Q methodology to quantitative, qualitative, and mixed methods," in The International Society for the Scientific Study of Subjectivity, Hamilton, Ontario, Canada, 2008.

[32] SSB, "National Statistics Norway" (Norwegian), 2009, http:// www.ssb.no/.

[33] W. Stephenson, "Newton's fifth rule and Q methodology: application to educational psychology," American Psychologist, vol. 35, no. 10, pp. 882-889, 1980.

[34] P. Taylor and D. J. Delprato, "Q-methodology in the study of child phenomenology," Psykological Record, vol. 44, no. 2, pp. 171-184, 1994.

[35] I. Størksen and A. A. Thorsen, "Young children's participation in a Q study with visual images: some comments on reliability and validity," Operant Subjectivity, vol. 4, no. 2, pp. 33-53, 2011.

[36] D. A. Harmon and T. S. Jones, Elementary Education: A Reference Book, Contemporary Education Issues, ABC-Clio, Santa Barbara, Calif, USA, 2005, D. Weil, Ed.

[37] D. V. M. Bishop, Uncommon Understanding: Development Disorders of Language Comprehension, Psychology Press, Hove, UK, 1997.

[38] S. Hart and R. Schwartz, Fra interaksjon til relasjon: tilknytning hos Winnicott, Bowlby, Stern, Schore og Fonagy, Gyldendal Akademisk, Oslo, Norway, 2009.

[39] A. Slade, "The implications of attachment theory and research for adult psychotherapy," in Handbook of Attachment: Theory, Research, and Clinical Applications, J. Cassidy and P. R. Shaver, Eds., The Guilford Press, New York, NY, USA, 2008. 
[40] F. Skårderud and B. Sommerfeldt, "Mentalization: a new theoretical and therapeutical concept," Tidsskrift for den Norske Laegeforening, vol. 9, no. 1, pp. 1066-1069, 2008 (Norwegian).

[41] J. R. Brown, The I in Science: Training to Utilize Subjectivity in Research, Scandiantian University Press, Oslo, Norway, 1996.

[42] M. Hedegaard and M. Fleer, Studying Children: A CulturalHistorical Approach, Open University Press, Glasgow, UK, 2008.

[43] S. Heath, V. Charles, G. Crow, and R. Wiles, "Informed consent, gatekeepers and go-betweens: negotiating consent in childand youth-orientated institutions," British Educational Research Journal, vol. 33, no. 3, pp. 403-417, 2007.

[44] W. Stephenson, "Against interpretation," Operant Subjectivity, vol. 6, no. 3, pp. 71-103, 1983. 

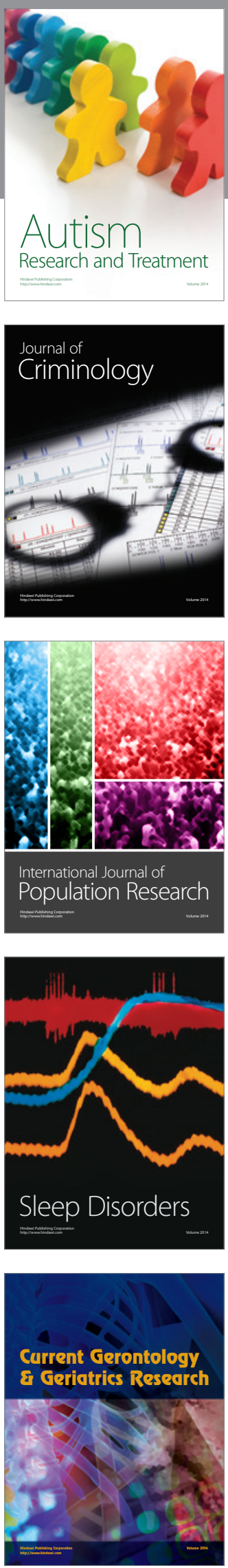
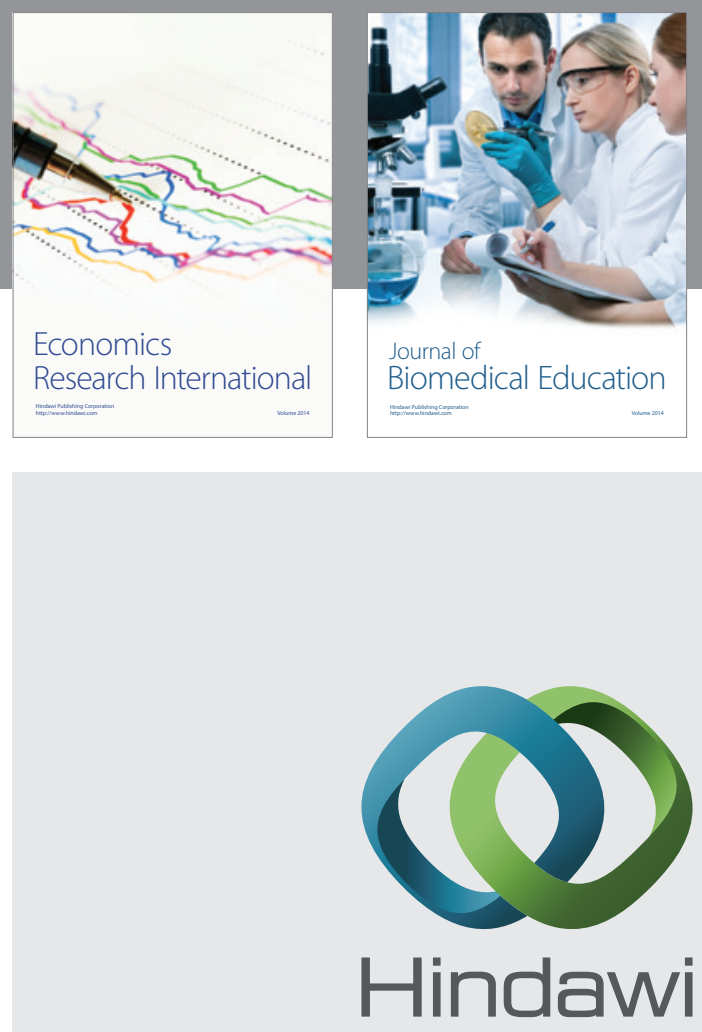

Submit your manuscripts at

http://www.hindawi.com
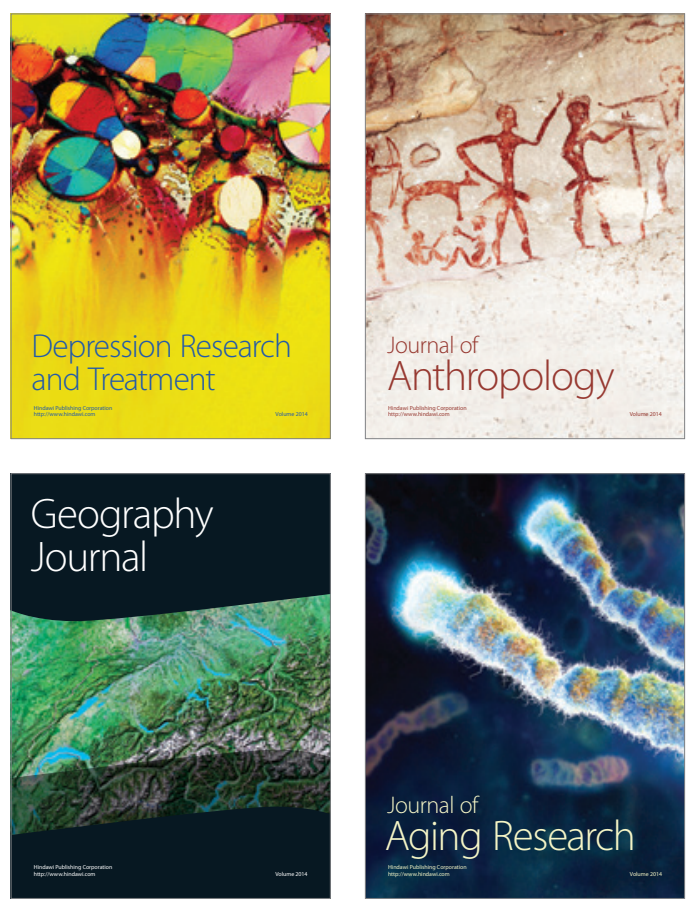
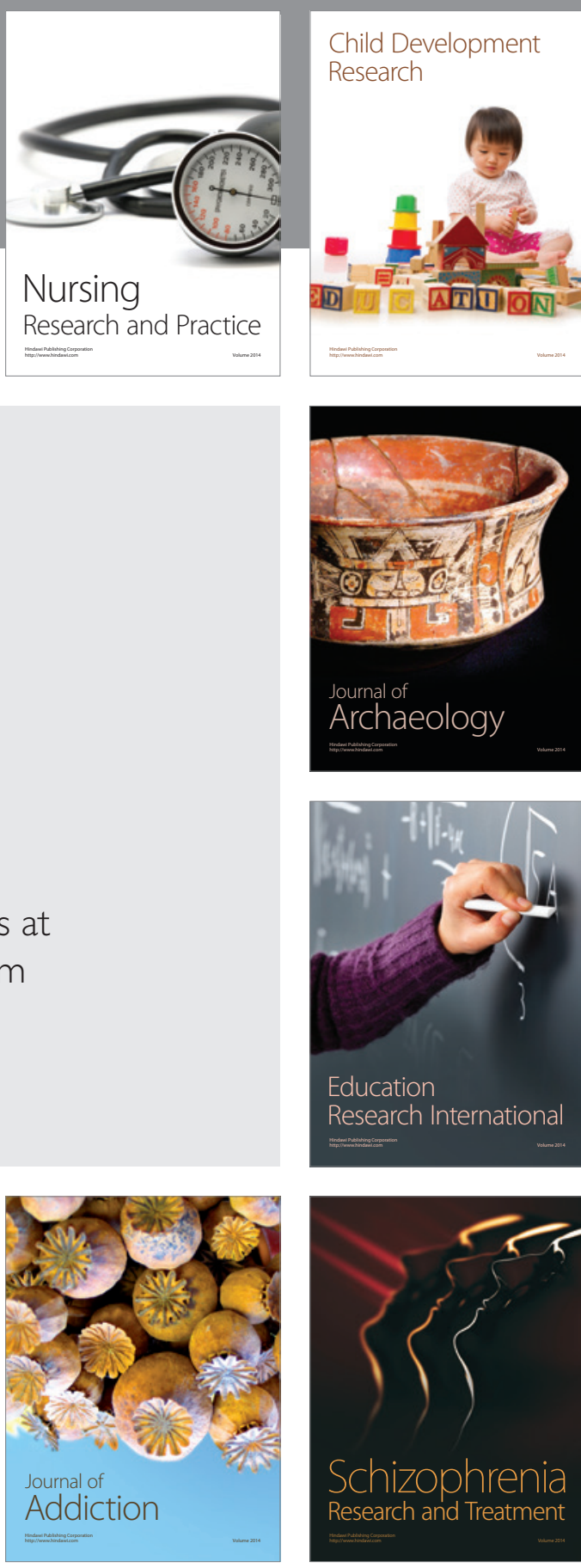

(D)
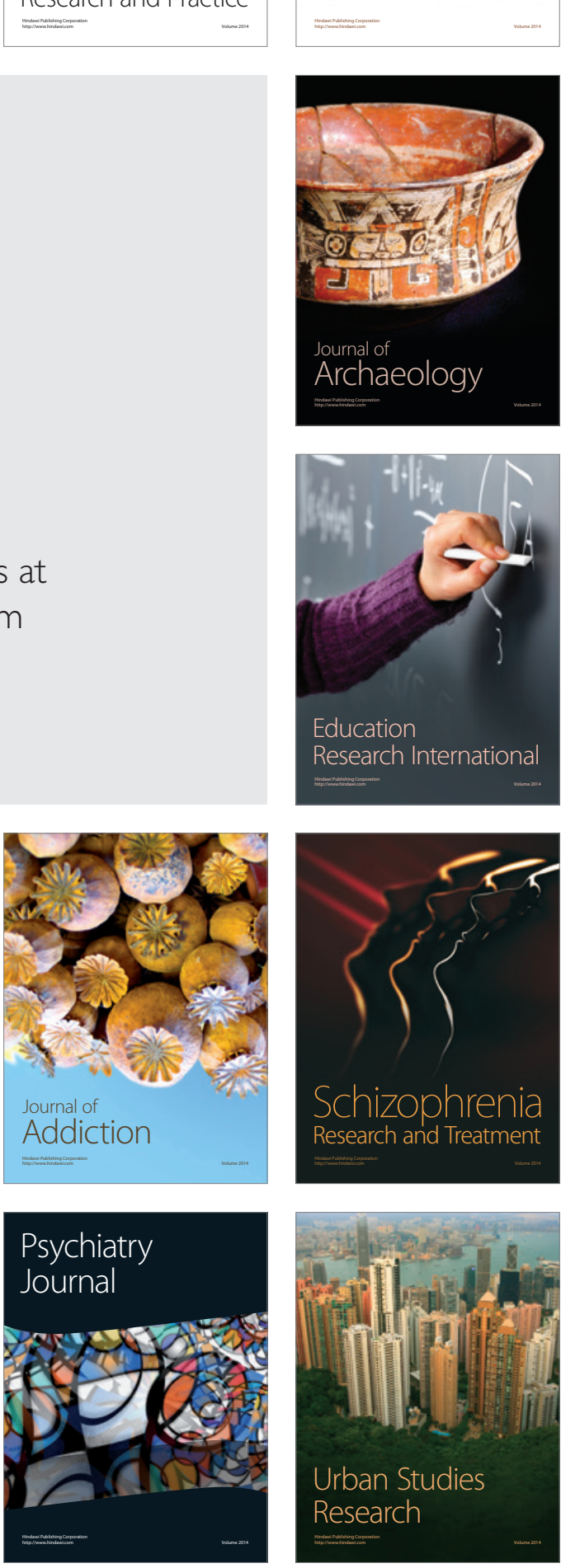